\title{
Food and Nutrition Trends: Eternal Life or Our Extinction?
}

\author{
İsmail Hakkı Tekiner* \\ Department of Nutrition and Dietetics, İstanbul Sabahattin Zaim University, Turkey
}

*Corresponding author: İsmail Hakkı Tekiner, Department of Nutrition and Dietetics, İstanbul Sabahattin Zaim University, Turkey.

Received Date: December 18, 2019

Published Date: January 13, 2020

\begin{abstract}
Four thousand years later, Gilgamesh's story still tells us valuable things about meaning of life, our inescapable mortality, and fighting for eternal life. Since the end of the World War II, food industries and stakeholders have been writing again a contemporary Epic of Gilgamesh offering nutrition and health challenges as if alleged paradigm-shifting divinity.
\end{abstract}

Keywords: Food; Nutrition; Trend; Eternal life; Extinction; Health challenge; Paradigm; Paradox

\section{Introduction}

Gilgamesh and his beloved friend Enkidu start a journey to conquer the god Humbaba. Our heroes battle Humbaba and kill the god with the help of another god Shamash. Things go so badly, and Humbaba curses them before dying. Enkidu becomes sick and dies shortly after. Endiku's death bludgeons Gilgamesh into making a second journey to discover the secret of eternal life, and then finds the magical plant of immortality. However, a serpent steals it. Eventually, Gilgamesh stops looking for youth-giving secret bows to the inevitable and goes back to Uruk in Mesopotamia to spend the rest of his life [1, 2].

The 1950s were a turning point, and clearly started transforming and re-orienting our food systems and societies. This transformation dramatically accelerating in the 1970s triggered mass-production and overconsumption, including food and nutrition systems, throughout the world by means of the neoliberal economic model [3].

Here we need to ask that question to ourselves; how food and nutrition systems evolved after the 1950s? After the end of the WW II, the stakeholders or neoliberal economic model in the need to generate profits intensively began to develop and implement new culture-based tools, including mass consumption, consumer, image, media cultures to be able to market newly invented products [4].
Lifestyles along with food and beverage purchase decisions in the world are mainly shaped by demographic changes, widespread electronic network, and shifting personal values. For instance, specialty foods and drinks are the third fastest-growing luxury category worldwide, after electronics and cars. Global consumers look for new products and solutions driving growth of health and wellness such as prevention of stress and anxiety, mild vision impairment, mental development, and gut health, and so on [5].

Interestingly, we see the reflections of this transformation in five Nobel Prizes Winners. Each made significant contributions to the history of food and nutrition such as; Pavlov on mammalian digestive systems, Eijkman and Hopkins on vitamins for health and disease prevention, Orr on equitable distribution of food and nutrition, Borlaug on disease-resistant crops to improved yields, and Amartya Sen on prevention or mitigation of famine [6]. This chronological order reveals that after 1945, Nobel Prizes also shifted from pure and health researches to economic, food and nutrition security related policies, as obviously seen.

We actually evaluate the probability of our species extinction from naturally occurring processes, as Snyder-Beattie et al. said. Such processes contain well-characterized risks such as asteroid impacts, super volcanic eruptions, mega earthquakes, and pandemic 
diseases as well as other risks that still remain unclear. However, However, Snyder-Beattie et al. warn us to focus on the risks from our own design rather than spending on existential risks. Being honest, many of today's food production systems and nutrition trends compromise the capacity of our blue planet to meet the food needs in the future [7]. Food and nutrition trends don't just have an impact on the human health, but also on the health of the Earth and all other existing species.

If so, what is the matter? Benjamin Franklin said, "we are all born ignorant, but one must work hard to remain stupid". His words would be assumed to be a call against ignorance in the solutions to food systems, which are becoming complex and challenging by time. It is a statement that given the evidence about the extinction caused by overconsumption in the planet, its climate, species and people, continuing to be ignorant equals sheer stupidity, and we do not need to be a genius to understand this. In this perspective, I see that each historical period reflects unique circumstances indeed. However, I criticize the final destination of food and nutrition trends in this era; eternal life or our inescapable mortality? even though the extinction is to some extent predictable.

We are entering an increasingly dangerous period of our history, as Stephen Hawking said. All we can say that Hawking's comments could have come before the nutrition and health challenging Epic of today's food and nutrition trends. This is a strange paradox, as Elizabeth A. Johnson says [8], and tells us strange things about eternal life such as gazing in wonder at Earth, and in contrary to, our inescapable mortality such as ravaging and depleting the natural world four thousand years later.

\section{Acknowledgement}

None.

\section{Conflict of interest}

No conflict of interest.

\section{References}

1. Shakiba F (2018) The image of snake in Elam and Jiroft sites in southwest and southeast of Iran and its comparison with zoroastrianism. Journal of Ancient History and Archaeology 5: 5-15.

2. Ian Chadwick I (2019) Gilgamesh four thousand years later.

3. Arthur Marwick Purdue (2016) The Transformative Impact of World War II.

4. Ashley Crossman (2019) A Sociological Definition of Popular Culture.

5. Elizabeth Sloan A (2019) Global Migration: Emerging Opportunities in Food and Drink.

6. Lisa Bramen (2011) Five Nobel Laureates Who Made Food History.

7. Snyder Beattie AE, Ord T, Bonsall MB (2019) An upper bound for the background rate of human extinction. Sci Rep 9(1): 11054.

8. Elizabeth A. Johnson (2001) God's Beloved Creation. 